\title{
CLINICAL AND RADIOGRAPHIC ASSESSMENT OF ZIRCONIA AND STAINLESS-STEEL CROWNS IN RESTORATION OF PRIMARY MOLARS
}

\author{
Mohamed A Wakwak", Samy Y ElBayoumy", Ibrahim F Barakat ${ }^{* * *}$
}

\begin{abstract}
Purpose: Assessment of zirconia and stainless steel crowns in restoration of primary molars(clinical and radiograph) Methods: One hundred and twenty randomly selected Egyptian children received bilateral crowns to first or second primary molars, one side was restored by stainless steel crowns (group A) and the other side was restored by zirconia crowns (group B) Results: There was significant increase in score of gingival index for both SSC and zirconia crowns after 1 week and after 6 months but increase in score was more in SSC than zirconia crowns. There was significant increase in score of debris index for SSC after 1 week and after 6 months and there was insignificant increase in score for zirconia crowns after 1 week and after 6 months. There was no statistically significant difference in alveolar bone height in both groups (zirconia and SSCs) Immediately after cementation and after 6 months Conclusions: Zirconia crowns presented to be an excellent choice for primary posterior teeth full coverage restorations. Zirconia crowns performed better than SSCs in the aspect of esthetic, gingival response and prevention of plaque adhesion.
\end{abstract}

\section{INTRODUCTION}

Primary teeth play an important role in growth and development of children. Attempts to maintain the primary teeth until the eruption of their permanent successors have resulted in the introduction of many restorative materials and techniques ${ }^{(1)}$. The stainless-steel crowns are often the first choice for the repair of severely damaged primary teeth and have been one of the most effective and efficient methods of tooth restoration in pediatric dentistry since Humphrey first used them in pediatric patients in $1950^{(2)}$. They are used to restore primary or permanent teeth with extensive or multisource cavities, cervical decalcification and/or developmental defects ${ }^{(3)}$. The stainless-steel crowns have many advantages over other crown types and dental restorative materials ${ }^{(4,5)}$. First, their life span is the same as that of an intact primary tooth. Second, they provide protection to the residual tooth structure that may have been weakened after excessive caries removal. Third, the technique sensitivity or the risk of making errors during their application is low. Fourth, their cost is $\operatorname{low}^{(6)}$. Despite many advantages, the metal appearance of these crowns is unpleasant to the parents and children and they prefer tooth-colored restorations to silver-colored fillings regardless of location of restorations ${ }^{(7)}$. Inflammation of the surrounding gingival tissue is problem frequently associated with stainless steel crowns. The incidence of gingivitis has been reported to be higher around poorly fitting crowns than around the crowns considered to be well adapted ${ }^{(8)}$. Considering the increasing demand for esthetic restorations, several treatment options have been proposed for primary teeth to overcome

* Assistant Lecturer, Pedodontics and Oral Health Department, Faculty of Dental Medicine, Al-Azhar University (Assuit Branch).

** Professor, Pedodontics and Oral Health Department, Faculty of Dental Medicine, Boys, Cairo, Al-Azhar University *** Assistant Professor, Pedodontics and Oral Health Department, Faculty of Dental Medicine, Boys, Cairo, Al-Azhar University. 
this problem such as strip crowns, pre-veneered stainless-steel crowns and zirconia crowns ${ }^{(9,10)}$. Zirconia crowns are the most recent type of esthetic crowns for primary teeth. Zirconia, also known as "ceramic steel", has reasonable aesthetics and has excellent mechanical properties ${ }^{(11,12)}$. There are only a few studies that have informed on gingival health, the clinical success, and the clinical performance of primary molar teeth restored with a pre-fabricated esthetic crown ${ }^{(13)}$. So, this study was directed to evaluate effect of both zirconia and stainless-steel crowns on oral hygiene and microbial accumulation.

\section{MATERIALS AND METHODS}

The study was randomized clinical trial. The study approval was taken from parents or guardians by consent form. Parents were informed about the purpose of the study. This study was carried out on one hundred and twenty randomly selected Egyptian children from the Pedodontics Outpatients Clinic, Faculty of Dental Medicine, Al-Azhar University. Their age was ranged from 4 to 9 years. All children received bilateral crowns to first or second primary molars, one side was restored by stainless steel crowns (group A) and the other side was restored by zirconia crowns (group B).

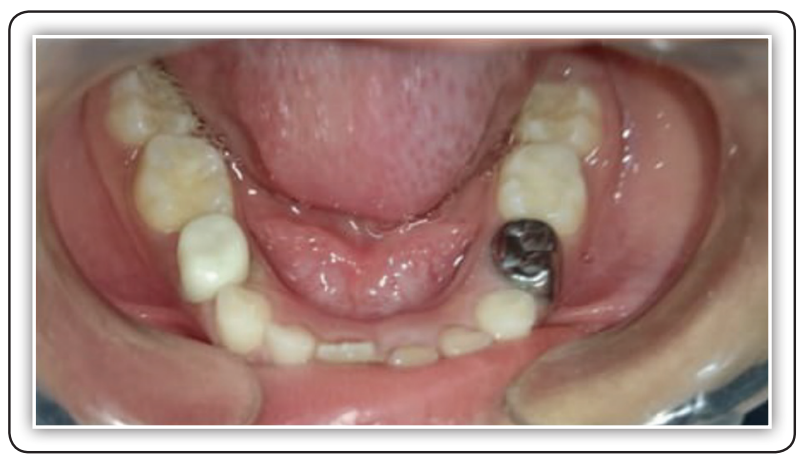

FIG (1) Zirconia and st.sl. crowns

\section{Clinical evaluation:}

\section{I- Gingival health and oral hygiene ${ }^{(14)}$ : -}

Gingival index and oral hygiene index using debris index and have been measured by passing an explorer tip gently within the sulcus on the tooth's mesial, distal, buccal, and lingual surface of each crown 1 week after cementation after 6 months

The gingival index was scored on a scale of 0 to 3 where;

$0=$ normal gingiva

$1=$ the presence of mild inflammation, slight change in gingival color, negligible edema, and no bleeding on probing

$2=$ moderate inflammation, gingival redness edema and glazing, and bleeding on probing

$3=$ severe inflammation, marked gingival redness and edema, ulceration, and a tendency to spontaneous bleeding.

The debris index was scored on a scale of 0 to 3 , where

$0=$ no debris

$1=$ soft debris covering less than one third of tooth surface

$2=$ soft debris covering more than one third of tooth surface but not more than two thirds of tooth surface

$3=$ soft debris covering more than two thirds of tooth surface.

\section{II- Radiographic evaluation ${ }^{(15):}$ -}

Two standardized digital periapical x- ray films were made for each crown, one immediately after cementation of crown and the other after 6 months from cementation. Radiograph was evaluated by change in the linear measurement of alveolar bone height from end of both stainless steel and zirconia crowns to the crest of alveolar bone between cementation of crowns and after 6 months. 


\section{Statistical analysis}

The mean and standard deviation values were calculated. Data were explored for normality using Kolmogorov-Smirnov and Shapiro-Wilk tests, data for alveolar bone height showed parametric (normal) distribution, while data for debris index and gingival index showed non-parametric (notnormal) distribution for parametric data; Repeated measure ANOVA was used to compare between more than two groups in related samples. The significance level was set at $\mathrm{P} \leq 0.05$.

\section{RESULTS}

\section{I- Gingival index results:}

After 1 week: There was a statistically significant difference between (Zirconia) and (Stainless steel) where $(p=0.026)$. The highest mean value was found in (Stainless steel) while the least mean value was found in (Zirconia) After 6 months: There was a statistically significant difference between (Zirconia) and (Stainless steel) where $(p=0.013)$. The highest mean value was found in (Stainless steel) while the least mean value was found in (Zirconia).

TABLE (1): Comparison between group A (stainless steel group) and group B (Zirconia group) regarding gingival index score.

\begin{tabular}{|c|c|c|c|c|c|}
\hline \multirow{3}{*}{ Variables } & \multicolumn{5}{|c|}{ Gingival index } \\
\hline & \multicolumn{2}{|c|}{ Zirconia } & \multicolumn{2}{|c|}{ Stainless steel } & \multirow[t]{2}{*}{ p-value } \\
\hline & Mean & SD $( \pm)$ & Mean & SD $( \pm)$ & \\
\hline $\begin{array}{c}\text { After } 1 \\
\text { week }\end{array}$ & $0.17^{\mathrm{bB}}$ & 0.16 & $0.40^{\mathrm{bA}}$ & 0.36 & $0.026 *$ \\
\hline $\begin{array}{l}\text { After } 6 \\
\text { months }\end{array}$ & $0.29^{\mathrm{aB}}$ & 0.14 & $0.71^{\mathrm{aA}}$ & 0.46 & $0.010 *$ \\
\hline p-value & \multicolumn{2}{|c|}{$0.014 *$} & \multicolumn{2}{|c|}{$0.006 *$} & \\
\hline
\end{tabular}

Means with different small letters in the same column indicate statistically significance difference, means with different capital letters in the same raw indicate statistically significance difference *; significant $(p<0.05) \quad n s ;$ non-significant $(p>0.05)$

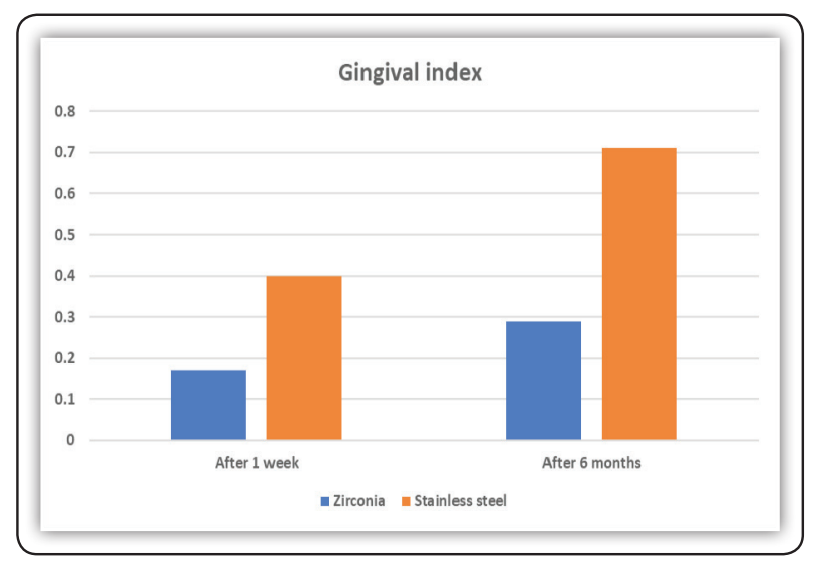

FIG (2) Bar chart representing comparison of gingival index between different groups

\section{II-Debris index results}

After 1 week: There was a statistically significant difference between (Zirconia) and (Stainless steel) where $(p=0.008)$. The highest mean value was found in (Stainless steel) while the least mean value was found in (Zirconia). After 6 months: There was a statistically significant difference between (Zirconia) and (Stainless steel) where $(p=0.013)$. The highest mean value was found in (Stainless steel) while the least mean value was found in (Zirconia).

\section{III- Radiographic evaluation results:}

Immediately after crown cementation: There was no statistically significant difference in alveolaer bone height between margins of crowns and crest of alveolar bone between (Zirconia)and (Stainless steel) where $(p=0.255)$. The highest mean value was found in (Stainless steel) while the least mean value was found in (Zirconia). After 6 months: There was no statistically significant difference in alveolaer bone height between margins of crowns and crest of alveolar bone between (Zirconia) and (Stainless steel) where $(p=0.254)$. The highest mean value was found in (Stainless steel) while the least mean value was found in (Zirconia). 
TABLE (2): Comparison between group A (stainless steel group) and group B (Zirconia group) regarding alveolar bone height.

\begin{tabular}{|c|c|c|c|c|c|}
\hline \multirow{3}{*}{ Variables } & \multicolumn{5}{|c|}{ Alveolar bone height } \\
\hline & \multicolumn{2}{|c|}{ Zirconia } & \multicolumn{2}{|c|}{ Stainless steel } & \multirow{2}{*}{ p-value } \\
\hline & Mean & $\mathrm{SD}( \pm)$ & Mean & SD $( \pm)$ & \\
\hline Immediately & $1.13^{\mathrm{aA}}$ & 0.31 & $1.23^{\mathrm{aA}}$ & 0.35 & $0.255 n s$ \\
\hline $\begin{array}{l}\text { After } 6 \\
\text { months }\end{array}$ & $1.16^{\mathrm{aA}}$ & 0.31 & $1.25^{\mathrm{aA}}$ & 0.35 & $0.254 \mathrm{~ns}$ \\
\hline p-value & \multicolumn{2}{|c|}{$0.082 n s$} & \multicolumn{2}{|c|}{$0.082 n s$} & \\
\hline
\end{tabular}

Means with different small letters in the same column indicate statistically significance difference, means with different capital letters in the same raw indicate statistically significance difference ${ }^{*}$; significant $(p<0.05) \quad n s ;$ non-significant $(p>0.05)$

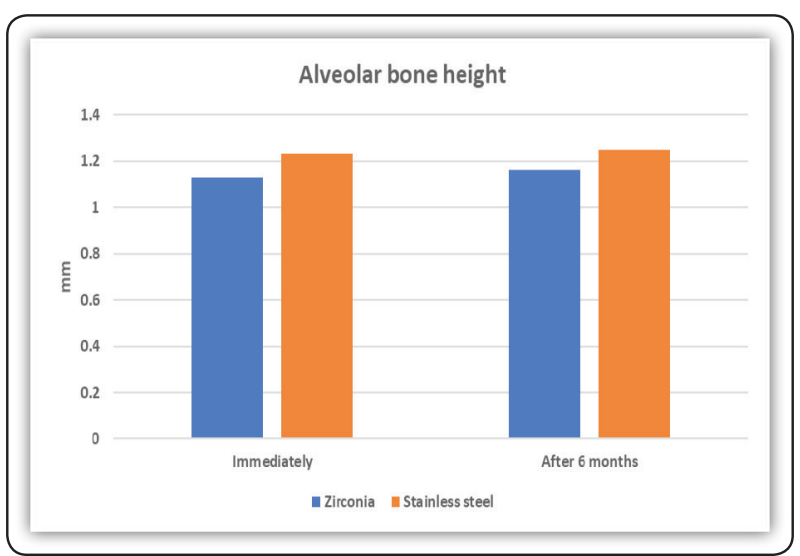

FIG (3) Bar chart representing comparison between Alveolar bone height of different groups

\section{DISCUSSION}

SSCs have been recommended to restore badly broken teeth and are considered to be superior to large multi surface amalgam restorations. Although SSCs are considered as the best treatment modality for teeth with extensive caries lesions or pulpotomized tooth, their use fails to meet the esthetic demands of the patient and the parents because of its unsightly metallic appearance ${ }^{(16)}$. The demand for esthetics has grown significantly for adults and children alike ${ }^{(9)}$. In the last decade, esthetic crowns for primary molars appeared on the market ${ }^{(15)}$. Due to their excellent properties, white color and superior biocompatibility; preformed zirconia crowns are being evaluated as an alternative to preformed SCCs. Through evaluation of gingival health, score of gingival index and debris index was taken for both SSC and zirconia crowns after 1 week and after 6 months. Regarding to gingival index there was significant increase in score for both SSC and zirconia crowns after 1 week and after 6 months but increase in score was more in SSC than zirconia crowns. These results may be due to poor oral hygiene of patient. Results showed that gingival health was better in teeth restored with zirconia crowns than those which treated with SSCs and these results may be due to remarkable biocompatibility of zirconia which lead to the lower tendency of plaque build-up and thus lower chance of gingival irritation. Regarding to debris index there was significant increase in score for SSC after 1 week and after 6 months and there was insignificant increase in score for zirconia crowns after 1 week and after 6 months. These results may be due to higher polished and smooth surfaces of zirconia crowns than SSC that lead to the lower tendency of debris accumulation to zirconia surfaces. These results in agreement with Kara N. et al. that compare oral hygiene and the gingival health between 3 types of crowns SSC, veneered SSCS and Nusmile zirconia crowns and reported that amount of plaque that accumulated on the teeth that have been restored with an NS crown, was lower than found on teeth that were restored with an SSC at the end of study however they found that plaque did not accumulate for the first 9 months around the teeth that were restored with an SSC because of the smooth-surfaces of the SSC In their study, they found that all restorations were associated with mild gingivitis, whose presence in all instances was independent of the crown type ${ }^{(17)}$. Also, Abdulhadi B. eet al. ${ }^{(8)}$ postulated that both zirconia and SSC have significant changes toward 
gingival health through all follow up points, however zirconia performed better when compared to SSC. Also, the zirconia crowns group presented fewer plaque accumulations during the follow-up periods and also improved with time. On the other hand, SSCs showed more plaque accumulations. Another study Walia et al. ${ }^{(19)}$ examined zirconia crowns on primary anterior teeth that show favorable gingival health toward those crowns when compared with strip crowns and preveneered SSCs and these results attributed due to zirconia as tooth material is highly biocompatible and possesses a polished and smooth surface leading to less plaque accumulation and hence less gingival irritation. On the other hand, results of current study disagree with Raslan N. et al. that reported gingival health around SSCs was better than that around the esthetic veneered crowns. This difference was attributed to the bulbosity of the composite veneer on the commercial esthetic crowns ${ }^{(20)}$. Also, these results supported by Fuks et al. who reported the esthetic preveneered crowns result in poor gingival health and attributed these results due to the bulk of the veneer on the esthetic crown, resulting in a thicker margin ${ }^{(21)}$ ? Also, Sharaf A. et al. ${ }^{(15)}$ concluded that stainless steel crowns had no harmful effect on the gingival health provided that good oral hygiene level was maintained. Through evaluation of alveolar bone height between margins of crowns and crest of alveolar bone (Immediately after cementation) and (After 6 months), There was no statistically significant difference in alveolar bone height in both groups (zirconia and SSCs). These results may be due to good marginal adaptation of crowns, good crown extensions and maintaining intact contact between teeth. However, there are limited literatures available in terms of effect of crown margins on interproximal bone resorption in primary molars. These results are accordance with Raslan N. et al. and Ram. et al. ${ }^{(13,20)}$ who reported no resorption was noticed in both SSCs and esthetic preveneered crowns. These results supported by finding of American Academy of Periodontology which postulated that alveolar bone resorption in the primary dentition is uncommon and can be caused by other factors such as certain systemic diseases. Moreover, the presence of severe periodontitis in children and adolescents may be an early sign of systemic disease ${ }^{(22)}$. Also, Elqousy A.

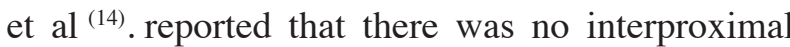
bone resorption when preformed SSCs as restoration for pulpotomized primary molar. However, there was significant bone resorption when SSCs have been used for restoration of pulpectomized primary molar and attributed these results due to other factors except SSCs placement. On the other hand, Sharaf A. et al. ${ }^{(15)}$ who reported alveolar bone loss was associated with stainless steel crowns that were judged radiographically as non-satisfactory

\section{CONCLUSIONS}

Zirconia crowns performed better than SSCs in the aspect of esthetic, gingival response and prevention of plaque retention. While interproximal bone resorption was not significantly affected by either crown marginal extension or adaptation for both SSCs and zirconia crowns

\section{RECOMMENDATION}

Longer follow up periods are recommended to observe long term effect of both SSCs or zirconia crowns on alveolar bone height

\section{REFERENCES}

1. Afshar H, Sabeti A \&Shahrabi M. Comparison of primary molar crown dimensions with stainless steel crowns in a sample of Iranian children JODDD.2015;9(2):87-91

2. Cheo J, Bae I \&Noh T. Wear of primary teeth caused by opposed all ceramic or stainless-steel crowns. J Adv Prosthodont. 2016; 8:43-52

3. Sonmez D\&Duruturk L. Success rate of calcium hydroxide pulpotomy in primary molars restored with amalgam and stainless-steel crowns. Br Dent J. 2010; 9:18-22

4. Randall R. Preformed metal crowns for primary and permanent molar teeth: review of the literature. Pediatr Dent. 2002; $24: 489-500$ 
5. Zagdwon A, Fayle S \& Pollard M. A prospective clinical trial comparing preformed metal crowns and cast restorations for defective first permanent molars. Eur J Paediatr Dent 2003;4(3):138-42.

6. Santamaria R, Innes N\&Machuliskene V. Caries Management Strategies for Primary Molars 1-Yr Randomized Control Trial. JDR .2014;93(11):13-8

7. Leith $\mathrm{R} \&$ Connell A. Clinical study evaluating success of 2 commercially available preveneered primary molar stainless-steel crowns. Pediatr Dent. 2011;33 (4):300-6.

8. Padbury A, Eber R \& Wang H. Interactions between the gingiva and the margin of restorations. J Clin Periodontol. 2003; 30:379-85

9. Zimmerman J, Feigal R, Till M\&Hodges J. Parental attitudes on restorative materials as factors influencing current use in pediatric dentistry. Pediatr Dent. 2009; 31:63-70.

10. Dhar V, Hsu K, Coll J, Ginsberg E\&Ball B. Evidencebased update of pediatric dental restorative procedures: dental materials. J Clin Pediatr Dent. 2015 ;39(4):303-10.

11. Gugnani N, Pandit I, Gupta M\&Nagpal J. Esthetic rehabilitation of primary anterior teeth using temporization material: novel approach. Int J Clin Pediatr Dent.2017;10(1):111-4.

12. Townsend J, Knoell O, Zhang J\& Zhu H. In vitro fracture resistance of three commercially available zirconia crowns for primary molars. Pediatr Dent.2014;36(5):125-9.

13. Ram D, Fuks A\&Eidelman E. Long-term clinical performance of esthetic primary molar crowns. Pediatr Dent. 2003; 25: 582-4.
14. Elqousy A, Elmasry E\&Abo Elnile G. Aclinical and radiographic evaluation of stainless-steel crown in second mandibular primary molars. Abstract of Master Thesis, Cairo University 2012.

15. Sharaf A \& Farsi M. A clinical and radiographic evaluation of stainless-steel crowns for primary molars. J Dent.2004;32(1):27-33.

16. Atieh M. Stainless steel crown versus modified open-sandwich restorations for primary molars: A 2-year randomized clinical trial. Ped Dent. 2008;18: 325-32.

17. Kara N \& Yilmaz Y. Assessment of oral hygiene and periodontal health around posterior primary molars after their restoration with various crown types. IJPD. 2014; 24: 303-13

18. Abdulhadi B, Abdullah M, Alaki S, Alamoudi N\& Attar M. Clinical evaluation between zirconia crowns and stainless-steel crowns in primary molars teeth. J Pediatr Dent. 2017; 5:21-7.

19. Walia T, Salami A, Bashiri R, Hamoodi O\& Rashid F. A randomised controlled trial of three aesthetic full-coronal restorations in primary maxillary teeth. Eur $\mathrm{J}$ Paediatr Dent. 2014; 15:113-8

20. Raslan N, Maroof H\& Nourallah A. Comparison between conventional and nanocomposite veneered stainless steel crowns: pilot study. IAJD.2016 ;5 (3):109-16

21. Fuks A, Ram D \& Eidelman E. Clinical performance of esthetic posterior crowns in primary molars: A pilot study. Pediatr Dent. 1999:21:445-8.

22. American Academy of Periodontology, Periodontal diseases of children and adolescents. Journal of Periodontology. 1996; 67:57-62. 